\title{
VÍCTIMAS DE VIOLENCIA SEXUAL: CONSTRUCCIÓN DE COMUNIDADES DE CREYENTES Y ACCESO A LA(S) JUSTICIA(S).
}

VICTIMS OF SEXUAL VIOLENCE: BUILDING COMMUNITIES OF BELIEVERS AND THE ACCESS TO JUSTICE.

VICTIMES DE VIOLANCE SEXUELLE: CONSTRUCTION DE COMMUNAUTÉS DE CROYANCES ET ACCÈS À LA ET/OU LES JUSTICES.

VÍTIMAS DA VIOLENNCIA SEXUAL: CONSTRUÇÃO DE COMUNIDADES CRENTES E ACESSO À(S) JUSTIÇA(S).

Taly Barán Attias

RESUMEN: Este artículo compara dos colectivos de víctimas de violencia sexual, por un lado, un grupo de mujeres que narran haber sido atacadas sexualmente por el Pombero (deidad proveniente de la mitología guaraní con fuerte arraigo en Paraguay y el nordeste argentino) y por otro, las mujeres víctimas de violencia sexual que logran inscribir su caso desde categorías coincidentes con el discurso legal. Se analizan las estrategias de protección y reparación desplegadas por cada colectivo y también cómo son recepcionados socialmente ambos tipos de casos de violencia sexual, a fin de pensar cómo se teje el reconocimiento al sufrimiento y las estrategias de creencia en torno a las víctimas. Es decir, se busca abonar a la comprensión de la relación entre la violación sexual, la construcción de creencias y el acceso a la justicia. Así también, a través de la comparación de casos, se apunta a la comprensión y tratamiento de la violencia sexual como hecho social.

Palabras clave: violencia sexual; creencias; víctimas; acceso a derechos; Pombero.

\footnotetext{
* Magister en Derechos Humanos y Democratización en América Latina y el Caribe; Becaria doctoral en el Centro de Estudios y Investigaciones Laborales (CEIL) del Consejo Nacional de Investigaciones Científicas y Técnicas (CONICET); Profesora de la Universidad Nacional Arturo Jauretche (UNAJ), Florencio Valera, Buenos Aires, Argentina; e-mail: talybaran@gmail.com
} 
Víctimas de violencia sexual: construcción de comunidades de creyentes y acceso a la(s) justicia(s).

ABSTRACT: This article compares two groups of victims of sexual violence; on one hand, a group of women who narrate having been sexually assaulted by the Pombero (a deity from the Guarani mythology with strong roots in Paraguay and north-eastern Argentina) and on the other hand, female victims of sexual violence who manage to symbolize their case from their own categories of legal discourse. Strategies for self-protection and reparation, unfolded by each group of victims, are analyzed in this piece, as well as how both types of sexual violence cases are socially received, in order to think how the recognition of their suffering and the belief strategies around the victims is woven. It seeks to contribute to the understanding of a connection between the act of sexual assault, the construction of beliefs and the access to justice. Likewise, through the comparison of cases, it focuses on the understanding and treatment of sexual violence as a social fact. Pombero.

keywords: sexual violence; beliefs; victims; access to rights;

$\boldsymbol{R E} \boldsymbol{S} \boldsymbol{U} \boldsymbol{M E}:$ Cet article compare deux groupes de personnes victimes de violence sexuelle. D'un côté, un groupe de femmes qui racontent avoir été attaquées sexuellement par le Pombero (divinité provenant de la mythologie guarani avec un fort ancrage au Paraguay et dans la région du nord-est argentin) et de l'autre, les femmes victimes de violence sexuelle qui ont réussi à faire rentrer leurs cas dans des catégories propres au discours juridique. Nous analyserons ici les stratégies de protection et de réparation déployées par chaque groupe de personnes et aussi comment sont reçus socialement les deux types de cas de violences sexuelles, afin de penser à la façon dont se tissent la reconnaissance de la souffrance et les stratégies de croyance autour des victimes. En d'autres mots, on cherchera à voir quelle est la relation entre la violence sexuelle, la construction de croyances et l'accès à la justice mais aussi à comprendre et ce, à travers la comparaison de différents cas, le traitement de la violence comme fait social.

Mots-clés: violence sexuelle; croyances; victimes; accès aux droits; Pombero.

RESUMO: Este artigo compara dois grupos de vitimas de violência sexual. De um lado, um grupo de mulheres que narra ter sido sexualmente agredido pelo Pombero (divindade da mitologia Guaraní com fortes raízes no Paraguai e no nordeste argentino) e, de outro, mulheres vitimas de violência sexual que conseguem registrar seus casos a partir de categorias próprias do discurso juridico. 
As estratégias de proteção e reparação implantadas por cada grupo são analisadas, bem como a forma como os dois tipos de casos de violência sexual são recebidos socialmente, a fim de refletir sobre como o reconhecimento do sofrimento e das estratégias de crença em torno das vitimas é tecido. Ou seja, busca-se atentar para a compreensão da relação entre estupro, construção de crenças e acesso à justiça. Além disso, por meio da comparação de casos, visa-se a compreensão e o tratamento da violência sexual como um fato social.

Palavras-chave: violência sexual; crenças; vítimas; acesso a direitos; Pombero.

\section{INTRODUCCIÓN}

No me importa quién haga las leyes de una sociedad, mientras yo pueda crear sus mitos.

Anónimo (en Rosana Reguillo, Los laberintos del miedo)

Cinco hombres violan colectivamente a una joven durante los festivales de San Fermín en el año 2016, se los conoce como "la manada", por el nombre de un grupo de WhatsApp en donde comparten con amigos anécdotas del episodio y prometen fotos. La justicia española dictamina que la víctima no opuso resistencia suficiente, por lo que se discute si hubo consentimiento. La Audiencia Provincial de Navarra decreta libertad provisional a los cinco implicados.

Inmediatamente se empiezan a dar manifestaciones espontáneas de mujeres en las principales ciudades de España para expresar su repudio a la sentencia, llevan carteles en donde se lee: "No estás sola. Somos tu manada". Mujeres de todo el mundo se pliegan al reclamo y salen a gritar "Yo te creo, hermana" y esa misma consigna es reapropiada por diversos colectivos en apoyo a otras tantas denuncias de violación.

¿Qué hay en esa frase que logra aglutinar la sensibilidad en torno a los casos de violencia sexual? ¿Una mujer es violada en masa y el grito es que yo le creo? ¿Es siquiera eso del orden de lo opinable? ¿Por qué no gritar justicia e interpelar a las instituciones del Estado? Feministas del mundo tejen una "comunidad de creyentes" como 
Victimas de violencia sexual: construcción de comunidades de creyentes y acceso a la(s) justicia(s).

antídoto a la provocación discursiva de los medios y de los agentes judiciales contra la víctima.

En este artículo nos centraremos en las víctimas de violencia sexual en un doble registro, por un lado, las mujeres que narran haber sido atacadas sexualmente por el Pombero (deidad proveniente de la mitología guaraní con fuerte arraigo en Paraguay y el nordeste argentino) y por otro, en las mujeres víctimas de violencia sexual que logran inscribir su caso judicialmente desde categorías propias del discurso legal. Atenderemos también a cómo son recepcionados socialmente los casos de violencia sexual, a fin de pensar cómo se teje el reconocimiento del sufrimiento y las estrategias de creencia en torno a las víctimas. Es decir, buscaremos reflexionar sobre la relación entre la violación sexual, la construcción de la creencia y el acceso a la justicia ¿Cómo influyen los modos del creer (en las instituciones, en seres mitológicos y en las víctimas) en el acceso a la justicia?

Para la realización del presente trabajo se efectuó trabajo de campo a lo largo del año 2018 en la ciudad de Yaguarón y en la localidad rural de Saguazú, ambas en el distrito de Yaguarón en Paraguay. También se ha realizado trabajo de campo en Asunción con mujeres migrantes del distrito antes mencionado. A su vez, se hicieron entrevistas en la ciudad de Resistencia en el chaco argentino. Metodológicamente, el trabajo contó con cuatro partes. En primer lugar se efectuaron una serie de entrevistas en profundidad a jóvenes y adultos de dichas localidades (16 mujeres y 6 varones). En segundo lugar, se llevó adelante un trabajo de tipo etnográfico (Guber, 2011) en la localidad de Saguazú que consistió en observación participante de las prácticas y tareas de la vida cotidiana de una familia de dicha localidad. En tercer lugar, se realizaron focus group con adultos asistentes regulares a misa y catequesis en la capilla Virgen de Caacupé, única capilla en la localidad de Saguazú. Esta estrategia fue el resultado de una emergencia de las entrevistas, donde recurrentemente se mencionaba a esa capilla como uno de los lugares preferenciales al que se acudía para solicitar protección de los ataques del Pombero. Finalmente, este trabajo se complementó con análisis de contenido de noticias de prensa gráfica y digital así como de foros de lectores de dichas noticias. 
Recapitulando, nos interesa profundizar aquí en los casos de mujeres que narran haber sido atacadas sexualmente por el Pombero, a fin de comprender las estrategias nativas de prevención y protección de los casos de violencia sexual. A su vez buscamos comparar cómo éstas últimas se relacionan con las estrategias de las mujeres víctimas que recurren a los canales de la justicia y las políticas públicas vigentes para dicho fin.

\section{La violencia sexual desde una perspectiva situada}

En lo que a violencia sexual se refiere, diversos autores han entendido la violencia sexual como un fenómeno universal que acompañó a las sociedades en distintas épocas, regímenes políticos y condiciones de existencia. Estos enfoques también coinciden en que la violación es un fenómeno estructural que tiene un efecto de disciplinamiento sobre las mujeres en su conjunto (Brownmiller, 1981; Sanday, 1981; Lerner, 1990; Pateman, 1993; Segato, 2010). Sin embargo la misma Segato explica que no en todas las sociedades la violación fue entendida de la misma manera, en las sociedades premodernas tendía a ser una práctica reglamentada como cuestión de Estado y de soberanía territorial, recién en la modernidad la violación va a ser entendida como un delito contra la persona agredida (2010, p. 26).

Desde los feminismos negros o autoras afines, surgieron una serie de críticas a este tipo de interpretaciones abstractas y universales sobre la violación, señalando ya sea que generalizan las prorrogativas del hombre blanco como comunes a todos los hombres (hooks, 2017) o por otra parte, señalando que fortalecen la imagen del hombre negro como violador y la mujer negra como depositaria de una promiscuidad que hace que nunca pueda ser considerada como víctima de una violación (Lerner, 1990; Davis, 2004; Segato, 2010).

Lo que van a señalar estas autoras con claridad es que la violación sexual asume variaciones no solo según la época, sino también teniendo en cuenta otros vectores como la clase, la raza, la sexualidad, las creencias, etc. A su vez, también van a advertir sobre la importancia de atender estas especificidades en las prácticas mili- 
Víctimas de violencia sexual: construcción de comunidades de creyentes y acceso a la(s) justicia(s).

tantes y en la producción académica (Davis 2004; hooks, 2017). Por su parte y desde otras latitudes, Veena Das ha planteado la dificultad de comprender desde las categorías disponibles en las ciencias sociales, la experiencia de dolor y agencia de las mujeres violadas de la India (2016, p.57).

Una crítica similar ha señalado Marta Lamas, quien advierte sobre los graves efectos de adoptar en latinoamérica la retórica sobre violencia sexual del norte. Más específicamente, la autora va a señalar que la reproducción del discurso hegemónico de las feministas radicales como clave interpretativa para el acoso sexual, ha reforzado un discurso puritano y victimista. A su vez, señala que esto instala una perspectiva esencialista en la que "la condición de victima es parte integral de la condición femenina" y "la sexualidad masculina es siempre una amenaza" (2018, p. 45). Sin embargo, lo que más preocupa a la autora, es que a partir de estos paradigmas importados sobre la violencia sexual, determinados sectores del feminismo terminan reclamando el endurecimiento de la justicia penal y reforzando la legitimidad de la política carcelaria (2018, p. 51).

En ese sentido, nos parece fundamental poder recuperar a partir de trabajos empíricos, reflexiones situadas en torno a la temática de la violencia sexual. Al respecto, entre los principales aportes sobre el tema en la región, existen valiosos trabajos que han planteado la necesidad de pensar de forma diferencial la experiencia de hombres y mujeres durante las dictaduras militares latinoamericanas. Éstos señalan la importancia de contar con un marco interpretativo específico para abordar la violencia sexual como práctica sistemática en contextos dictatoriales, ya que en muchos casos la violación queda invisibilizada dentro de la categoría general de “tortura" o "terror" (Fries, 2010; Mantilla, 2010; Sutton, 2015; Jelin, 2017; Sagot Rodríguez, 2017).

Estos trabajos señalan que la experiencia de violencia sexual no ha sido suficientemente recuperada en clave de memoria aún en democracia, inclusive señalan que se han dado lugar a prácticas de memoria que reproducen estereotipos de género. Para ilustrar eso, Jelín toma una cita de Crenzel en la que afirma que algunos datos o testimonios de violación no se han incluido en los informes de las 
comisiones de verdad "por considerarlos relativos al honor privado, por ser especialmente horrorosos como los casos de violaciones post mórtem o incluso porque podían afectar la credibilidad del informe en la opinión pública" (Jelín, 2017).

Desde otro campo disciplinar, en ámbito de la geografía feminista existen interesantes estudios que tematizan las formas en que la violencia sexual (propia o ajena) influye en la organización de la vida cotidiana de las mujeres, en la administración del tiempo y en los modos en que éstas habitan y transitan el espacio público a partir de imaginarios de seguridad y miedo al ataque sexual (Flores Pérez, 2014; Rodó de Zárate, 2018).

Entrando al plano de las creencias, desde los estudios del folklore hay trabajos que han abordado el cruce de la religiosidad popular y la violencia sexual, más específicamente la canonización popular de mujeres violadas y asesinadas, como los casos de Juana Figueroa en Salta (Calvetti, 1984; Coluccio, 2010) y la Almita Sivila en en Jujuy (Torres, 1974; Bazán, 2006; Bianchetti, 2012). El cruce entre sexualidad y mitología ha sido trabajado por diferentes autores (Citro, 2008; Tola, 2008), también considerando específicamente la violencia sexual y la simbolización mitológica (Gómez, 2008; Díaz Ledesma, 2011; Rebolledo Moller, 2013; Tarducci, 2013) generalmente circunscripto a comunidades indígenas.

A su vez, en lo que se refiere a violencia de género y violencia sexual, existe una rica producción estadística generada desde diversas ONGs, organizaciones feministas, organismos internacionales e incluso informes oficiales que evalúan anualmente el impacto del accionar judicial y las políticas públicas dirigidas a los grupos en situación de vulnerabilidad. Sin embargo, no ha sido suficientemente explorado el camino inverso, es decir, cómo se evalúa y complementa la eficacia de las alternativas instuticionales desde la perspectiva de los grupos vulnerables, específicamente a lo que a violencia sexual refiere. Por eso, no buscamos sólo presentar lo que la producción académica vigente sobre violencia sexual puede aportar a los casos de mujeres violadas por el Pombero, sino indagar en los aportes que pueden hacer estas experiencias a la comprensión, tematización y tratamiento de la violencia sexual como hecho social. 
Víctimas de violencia sexual: construcción de comunidades de creyentes y acceso a la(s) justi$\operatorname{cia}(s)$.

\section{VIVIR ENTRE DUENDES: PROCESOS DE SOCIALIZA- CIÓN, CIRCULACIÓN Y PROTECCIÓN DE LAS MUJERES Y NIÑAS}

\section{a.Relatos y experiencias en torno a la figura del Pombero}

La zona del nordeste argentino (Misiones, Formosa, Corrientes y Chaco) y la región oriental de Paraguay representan una regionalidad compartida y un entramado de prácticas culturales y lingüísticas propias, entre otras cosas, debido a la influencia de la lengua guaraní en contacto con el español. Sobre la variedad lingüística, se puede advertir la existencia de una valoración social desigual entre las mismas (Bourdieu, 1985; Bonnin, 2013) que, como veremos más adelante, repercute en el acceso a derechos. Son numerosos los estudios sobre imaginarios religiosos y formas de espiritualidad que ponen el foco en esta región debido a la creencia en los mitos cosmogónicos guaraníes, como por ejemplo, el Pombero (Cadogan, 1959; López Breard, 2011; Bondar, 2012; Fernández Bravo, 2015).

El Pombero es el más temido de los mitos guaraníes; en su versión más extendida, es una especie de duende, de figura similar a la humana, que se reconoce por sus silbidos durante la noche. Dicen que suele atacar "jovencitas" a quienes libera luego de saciar su apetito libidinoso. Se cuenta que muchas quedan embarazadas por él. Por eso los habitantes evitan pronunciar el nombre del Pombero, particularmente durante la noche, y se refieren a él como Karai-pyhare o con otros sobrenombres, porque no quieren despertar su ira.

E: En mi casa mi mamá no solía decir (Pombero) y a mí también me contaba que nunca hay que decirle por su nombre, o sea, llamarle, porque a ellos les molesta.

$\mathrm{T}:$ ¿Y preferís que le digamos de otra manera?

E: Bueno, mi mamá me contaba que la abuela de mi mamá le decía que le llamaban tío, tío le decían,por respeto.

(Entrevistada de 24 años, Asunción, Paraguay) 
Agradece generosamente a quien le deja tabaco, miel y aguardiente de caña, por ello, muchas familias preparan cada tarde esta ofrenda para librarse de su visita. Si la ofrenda desaparece, se sabe que es porque el Pombero la aceptó. Nadie se animaría a robarle "los gustos" al señor de la noche, uno de los tantos nombres que recibe de quienes temen pronunciar el original.

Lejos de ser un relato de leyenda o una creencia exclusivamente de las generaciones pasadas, hoy el Pombero está presente en las instituciones constructoras de subjetividades más poderosas de la región mencionada: el sistema educativo, los medios de comunicación, las industrias culturales y el mercado, y es a su vez reapropiado y resignificado en función de las transformaciones sociales:

En el 2004, con una discípula de la Universidad de Quilmes realizamos un trabajo en los asentamientos provincianos de aquel barrio. Y allí encontramos que el antiguo Pombero de los abuelos emigrados de esta región, seguía vivo en sus descendientes, aunque ya no mascaban tabaco, ahora fuman porros y están en las bailantas persiguiendo minitas (López Breard, 2006).

Como vemos, es habitual encontrarse con nuevos casos de ataques del Pombero que salen a la luz. En el año 2015 en San Pedro, Paraguay, se dio un caso que despertó interés mediático tanto en Paraguay como en Argentina, una mujer afirmó haber quedado embarazada producto de sistemáticas violaciones por parte del ser mitológico conocido como Pombero. Ante las malformaciones con las que nació el niño, la mujer acudió a las autoridades religiosas con un pedido desesperado de ayuda. Éstos negaron la existencia del Pombero, vinculándolo con otros casos de malformaciones a causa del avance de los agrotóxicos en la región.

En el 2016 en la localidad paraguaya de Villa Hayes las autoridades iniciaron una investigación por la muerte de una niña con sospechas de haber sido abusada sexualmente. Tras ser interrogada, la madre de la menor argumentó que "Oiméne karai pyhare (el señor de la noche) la habrá jugado". Los padres aseguraban su inocencia e insistían con la hipótesis del Pombero, sin embargo no se investigó sobre otros posibles responsables y los padres quedaron detenidos 
Víctimas de violencia sexual: construcción de comunidades de creyentes y acceso a la(s) justicia(s).

por incumplimiento del deber de cuidado. Así mismo, en la provincia de Misiones, Argentina, los vecinos de Colonia Milagros recuerdan un caso que dio el nombre al lugar, en 1996, el Pombero se llevó durante 6 días a una niña que fue encontrada con vida y totalmente desnuda en el monte. En la misma localidad, hubo un caso similar a mediados del 2016.

En julio de 2018 en la localidad paraguaya de San Pedro, una mujer fue encontrada en un pozo de agua de más de siete metros de altura en donde casi muere ahogada, ella aludió haber caído ahí por estar escapando del Pombero. En las entrevistas televisivas que dio la mujer luego de ser rescatada, contó que no era la primera vez que tenía un encuentro violento con este ser mitológico.

Lejos de ser los únicos casos, la interacción violenta con seres mitológicos como el Pombero es la forma en la que muchas mujeres simbolizan la violencia sexual de las que son víctimas. Es el modo en el que aprendieron a vivirlas, a partir de relatos fuertemente afectivizados que forman parte de la memoria familiar, dado que son los abuelos, padres y tíos los que narran historias similares con el Pombero.

\section{b.Estrategias de protección ante ataques del Pombero}

A continuación, desarrollaremos las estrategias nativas de cuidado que consisten en una forma de vivir la especialidad y la domesticidad del hogar, un aprendizaje del cuerpo sexuado y determinadas estrategias de culto. Las estrategias y prácticas de cuidado se dan en gran medida por fuera de las instituciones estatales y están vehiculizadas por la transmición de la memoria familiar (Pollak, 2006; Hernández, 2011).

Escuchábamos siempre, había muuuuuchas historias que contaba mi abuelo y eso, mi papá por ejemplo suele contar historias, que existe, que te lleva, te hace muchas otras cosas. Desde chiquita sabía yo eso porque de eso teníamos miedo entonces de noche no salíamos. De noche no salgo, no luego.

(Entrevistada de 32 años, Saguazú, Paraguay) 
Estos momentos son espacios de transmisión de memoria (Yerushalmi, 1989), en donde los miembros mayores de la familia introducen a los más jóvenes historias en donde parientes cercanos o incluso la misma persona narradora, han sido protagonistas de ataques por parte del Pombero. Ahí no sólo se comparten relatos familiares, sino también se despliega un saber que va de generación en generación, sobre estrategias de cuidado de las mujeres de la familia, que se va entretejiendo con las preocupaciones contemporáneas sobre la seguridad y el cuerpo de las niñas. A su vez, según lo recogido en el trabajo de campo, éstas historias son rememoradas constantemente en conversaciones familiares o con vecinos y amigos, por lo que estas enseñanzas son reactualizadas y afirmadas colectivamente numerosas veces a lo largo de la vida de cada mujer.

En esos espacios, se producen colectivamente "memorias para el futuro" (Das, 2916, p. 59) donde las niñas aprenden a cómo evitar ser violadas por el Pombero, pero también son enseñadas desde muy pequeñas que tienen un cuerpo sexuado, que pueden ser violadas y que otras mujeres de su familia lo han sido. Esos relatos también son una evocación a la memoria sexual de las mujeres de la familia, en donde se recuerdan las experiencias de sexo forzado de generación en generación y se van actualizando con relatos de nuevas víctimas de ataques sexuales por parte del Pombero.

Sin embargo, este modo de colectivizar las historias de violencia sexual de las mujeres de la familia no se traduce de modo alguno en denuncias a la justicia ni acceso a los programas de acompañamiento a víctimas de violencia sexual. Aún ante la aparición concreta de amenazas, es difícil que estas mujeres decidan acudir a la policía ni a la fiscalía en busca de ayuda. Un primer problema radica en la falta de contacto entre la simbolización que tienen estas familias sobre sus vivencias y el lenguaje jurídico estatal que hace que sigan transitándolo en soledad aun existiendo normativa y programas específicos para combatir la violencia sexual y de género. Estos fenómenos no se piensan en términos de "delito" sino desde otras epistemologías con préstamos de la cosmovisión guaraní, que tienen otras perspectivas de protección y reparación.

Como advierte Butler, las decisiones de acudir a la justicia son prácticas sociales, por ello determinados modos de "afirmación de los 
Victimas de violencia sexual: construcción de comunidades de creyentes y acceso a la(s) justicia(s).

derechos surgen donde las condiciones de interlocución pueden ser presupuestas, o mínimamente invocadas e incitadas cuando aún no están insititucionalizadas" (2010, p. 40). Por eso, el problema no es que las víctimas del Pombero decidan no recurrir a la justicia, sino que los canales institucionales bloquean el acceso de éstas mujeres a los mecanismos de la vía legal porque no les creen. Estas mujeres no son miembros de comunidades indígenas; por ende, no están comprendidas bajo la protección del derecho tradicional consuetudinario. Sin embargo, al simbolizar sus experiencias de violencia sexual desde la cosmovisión mitológica tampoco logran acceder a la justicia ordinaria.

En este contexto, estas mujeres elaboran sus propios mecanismos de protección que como ya hemos dicho, son transmitidos y practicados familiarmente. El principal cuidado a la hora de defenderse de los ataques del Pombero es no andar solas cuando cae la noche, en ese sentido, las mujeres organizan sus numerosas tareas del hogar para poder tener todo listo antes de la caída del sol, momento en el que deben mantenerse al interior del hogar, el único lugar en donde el duende rara vez accede. Vemos aquí cómo la propia espacialidad del hogar y la domesticidad están organizadas a partir del temor a la violencia sexual.

Y contaban casos todo el tiempo mi mamá y mi finada abuela también me contaba. Ellas creían muchísimo en eso y así cuando era de noche ya no salían más a hacer cualquier cosa, ya tenían que hacer todo antes que oscurezca. Yo a los 7, 8 años por ahí tenía escalofríos y siempre yo [lo] escuchaba en la noche.

(Entrevistada de 24 años, Asunción, Paraguay)

T: ¿Y en la pieza se está a salvo?

E: En la pieza, sí, aunque hay algunas chicas que..., viste que algunas veces la mayoría duerme [la ventana], todo abierto, así con shortcito, en pijama o sin pijama y algo así. Pero la verdad no creo, a cualquier mujer le puede también embarazar, no importa, con tal de que sea mujer, ya está (...) En la televisión pasó eso de la chica que se embarazó pero que no era de un hombre ni de su pareja, que era de un Pombero. Yo cuando escucho me asusto y tengo más miedo, para no salir más de noche también.

(Entrevistada de 21 años, Saguazú, Paraguay) 
Cuando esas estrategias de reclusión al hogar no resultan suficientes, muchas veces acuden a las autoridades religiosas (principalmente católicas), en pedido de apoyo. Las respuestas de los agentes de la religiosidad oficial varían según el lugar y los actores intervinientes y pueden ir desde el descrédito de estas creencias rotuladas como supersticiones, rezos para liberar a una persona u hogar de las visitas del Pombero, hasta la venta de productos como amuletos protectores específicos para dicho fin.

Estas "estrategias de culto" al Pombero consisten en prácticas preventivas (o de protección de sí), que refuerzan la responsabilidad de la víctima en caso de incumplimiento. Como explica Segato, la violación opera como una herramienta disciplinadora sobre el colectivo de mujeres (2010, p. 31), en ese sentido, dichos códigos de conducta operan sobre las mujeres más allá de que hayan tenido algún encuentro con el Pombero. Estas prácticas tienen su contraparte en el confinamiento espacial (restringido a lo doméstico) y a los roles asociados a este espacio y con el acatamiento de las prácticas de la religiosidad oficial.

...porque [el Pombero] les quiere llevar a las criaturas, le persigue mucho a los que no son bautizados, le atormenta mucho el tío [así le decía la entrevistada al Pombero para evitar nombrarlo]. Para que no te aparezca si no estás bautizada o si no, podés bautizarte con agua bendecida así para poner en agua de socorro se llama. El agua de socorro es una agua bendita que lo hace el párroco o una catequista también. Yo antes de bautizar a mis hijos lloraban mucho de noche como que se despertaban a cada rato, que no podían más dormir, y eso yo digo que es por el "tío" que les atormenta. Y cuando les bauticé ya estaban más tranquilos, ya dormían más.

(Entrevistada de 24 años, Asunción, Paraguay)

- Muchas veces también [el Pombero] le quiere llevar el bebé, si te descuidás te lleva tu bebé

- Para eso hay que rezar y poner por la puerta o por la ventana el rosario - una cinta roja por tu bebé con el anillo de tu... si eres casada tu anillo o sino de la abuela o alguien casado de iglesia que haya en la familia

(Focus group en Capilla Virgen de Caacupé, Saguazú, Paraguay) 
Víctimas de violencia sexual: construcción de comunidades de creyentes y acceso a la(s) justicia(s).

De este modo podemos entender la figura del Pombero como un agente moralizador que permite la conservación de un determinado orden a partir de una regulación social (espacio-temporal) que el mito introduce en la vida y el cuerpo de las mujeres. De hecho este efecto regulatorio que tiene el Pombero, se articula con la idea que desarrollaremos más adelante de comprender también la "violación como restauración de un orden patriarcal” (Segato,2010, p. 37).

\section{¿QUÉ HACER CON LO VIVIDO? ALTERNATIVAS (Y OBS- TÁCULOS) INSTITUCIONALES DE GESTIÓN DE LA EXPE- RIENCIA SEXUAL VIOLENTA}

Así como las familias creyentes evitan pronunciar el nombre del Pombero como estrategia de protección, esa dificultad o imposibilidad de nombrar lo temido también opera en otros aspectos de la vida, como por ejemplo en torno a los casos de violencia sexual muchas veces conocidos como "secretos de familia". En un contexto social y familiar que empuja a las víctimas de violencia sexual a callar, en donde las situaciones y el vocabulario es confuso y el sufrimiento muy grande, las palabras aparecen sólo cuando pueden ser pronunciadas.

Como denuncia la escritora Belén López Peiró, "de la violencia sexual siempre se habla en tercera persona". Lo mismo preocupó a los miembros de las Comisiones de Verdad y Reparación de Guatemala y Sudáfrica: de los numerosos testimonios de violencia sexual que recogieron, las mujeres eran siempre testigos y no protagonistas, las mujeres no hablaban sobre sí mismas (Theidon, 2011, p. 49). El reconocimiento de la dificultad que tiene una víctima para procesar lo vivido y animarse a hablar ha llevado, incluso, a la adecuación de los códigos penales reconociendo que los ataques de índole sexual no pueden prescribir en los mismos plazos que otro tipo de delitos.

En materia de protección a las mujeres, tanto Paraguay como Argentina han firmado y ratificado todos los tratados y protocolos tanto a escala internacional, como es la Convención para la Eliminación de todas las formas de Discriminación contra la Mujer (CEDAW, su sigla en inglés), como en el ámbito interamericano, en el caso de la 
Convención Interamericana para Prevenir, Sancionar y Erradicar la Violencia contra la Mujer. Con ello, los países se han comprometido a generar medidas efectivas de prevención de la violencia y protección a las mujeres, ya sea la adecuación normativa, designación de partidas presupuestarias y realización de políticas públicas efectivas. Sin embargo, nos interesa señalar que de facto, se da una vivencia diferencial del acceso a la protección de éstos derechos.

Los datos de la Encuesta Nacional de Victimización (INDEC 2017, Argentina), indican que el $87,4 \%$ de las personas que vivieron agresiones sexuales en la Argentina no ha acudido a institución alguna a realizar la denuncia. Dentro de los delitos violentos, la agresión sexual es la que tiene la tasa más alta de no denuncia. ¿Cómo escuchar estos silencios de las víctimas? Una primera explicación puede deberse, siguiendo los aportes de Hercovich (2000), a la dificultad de narrar hechos traumáticos y/o la falta de apoyo del entorno familiar para que esas historias salgan de la esfera privada. Aquí opera fuertemente el sentimiento de vergüenza, no solo de las víctimas sino también de sus familias (recordemos la denominación jurídica "delitos contra el honor y la honestidad"), porque significa para ellos "admitir que fueron incapaces de proteger a "sus" mujeres" (Theidon, 2011, p. 52).

Otro motivo para la no denuncia puede ser la desconfianza en la justicia como modo de resolución, sobre todo para las mujeres guaraní-hablantes. "Si bien en Paraguay el guaraní es la lengua mayoritaria, se encuentra de facto, subordinado al español y no es adoptada por el Estado en la comunicación con sus ciudadanos" (Bonnin, 2014, p.274). Para las mujeres guaraní-hablantes, el Estado está asociado al idioma español y es experimentado con un plus de ajenidad y dificultad a la hora de ejercer derechos que, a su vez, requieren lecto-comprensión en ese idioma: desde carteles, formularios y muchas veces hasta el diálogo con los funcionarios estatales requieren el uso del español.

E1: Y yo por eso me voy con mamá al hospital porque los doctores por ejemplo hay más que hablan en castellano y el doctor le está diciendo en castellano che (palabra guaraní para decir yo) atraducí 
Victimas de violencia sexual: construcción de comunidades de creyentes y acceso a la(s) justi-

cia $(s)$.

mamá en guaraní.

E2: Y cuando uno se va hacia Asunción a hacer un trámite o a atenderse ya es difícil, tiene que ir sí o sí alguien que sepa hablar el castellano para hablar ahí, acá en Yaguarón por ejemplo o en Itá si vos le hablás en guaraní, te pueden atender en guaraní. La receta y los carteles y eso sí, siempre en castellano todo.

(Entrevista grupal realizada en la localidad de Saguazú en Yaguarón, Paraguay)

$\mathrm{Si}$ a la valoración desigual de las lenguas agregamos que las mujeres narran haber sido violadas por un ser mitológico como el Pombero, la falta de diálogo y confianza en los agentes institucionales de la justicia es mucho mayor. De todos modos, la experiencia de sentirse desacreditada por parte de los agentes estatales a la hora de dar testimonio sobre violencia de género, es una vivencia compartida también por las mujeres que narran otros tipos de ataques ajenos al Pombero.

R: Solamente me fui a poner la denuncia (...) Mi mamá me dijo que hiciera un papel porque el papá aparece y quiere agarrarle a las criaturas mientras yo estoy trabajando en Asunción.

T: ¿Y ahí como te fue con el tramite?

$\mathrm{R}$ : Más o menos, porque dicen que algunos se quieren separar y vienen y después al final nada no hacen, que se van otra vez con su marido, y al final el papeleo sale de balde. Entonces ya no me fui más (...) Dijeron que a veces de balde nomas vienen a denunciar al marido porque al final enseguida se van otra vez con el marido.

(Entrevistada de 30 años, Yaguarón, Paraguay)

Aun partiendo de la certeza de contar con un enorme sub-registro de casos, la Encuesta Nacional de Demografía y Salud Sexual y Reproductiva (CEPEP 2008, Paraguay) revela una clara vivencia diferencial de la violencia sexual según el idioma hablado. Según la misma, el 11,2\% de las mujeres guaraní-hablantes declaró haber sido víctimas de sexo forzado alguna vez en sus vidas, mientras que entre las hispanohablantes la cifra es de 5,4\%. A su vez, el 9\% de las mujeres que hablan guaraní reconocíeron haber sufrido abuso sexual y entre las hispanoablantes un 6,5\% (p.42). Sin embargo, la relación es inversa cuando se refiere a la realización de denuncias. 
Eso significa que hay mujeres más expuestas a ser violadas que otras y, aunque existen leyes para protegerlas, el acceso a éstas es diferencial en relación al idioma de la ley: es decir, no solo nos referimos al castellano, el idioma en el cual está pensado y escrito el marco jurídico, sino también al lenguaje de las categorías jurídicas con las que se simbolizan, interpretan y narran las violaciones vividas.

Los aportes de Inés Hercovich (2000) permiten dar un paso más en la comprensión de la no denuncia. Para la autora, las instituciones patriarcales como la justicia y la religión han restringido la figura de víctima a alguien que no tuvo ningún intercambio voluntario con el agresor (por ejemplo subir a su auto, besarlo, conversar) y poseedora de heridas "mostrables", consecuencia de haber opuesto resistencia activa al acto de su violación. A partir de numerosas entrevistas a mujeres violadas, Hercovich explica que ante el temor a ser asesinadas, las mujeres terminan "negociando sexo por vida" con sus agresores, por lo que la exigencia de ese tipo de resistencia lleva a las mujeres a dudar de su condición de víctimas.

\section{FORMAS LEGITIMADAS DE VICTIMIZACIÓN: EL GUIÓN DE LA VIOLACIÓN COMO CAPITAL NARRATIVO}

el mundo es un museo en el que los celadores puede que sean amorosos la mayor parte del tiempo, pero no por eso dejan de imponer las reglas (...) A cambio del amor están obligados a sostener el mito de su inocencia. No solo tienen que ser inocentes, tienen que representarlo. República Luminosa por Andrés Barba

Como se ha señalado desde la teorización sobre el concepto de "mala víctima" (Hercovich, 2000; Despentes, 2013; Arduino, 2014; Silvestri, 2017; Tomasini, 2017), frente a las mujeres que se animan a romper el silencio de las violencias sexuales, existe un mecanismo que irrumpe con sorprendente coordinación: unidades autónomas de desconfianza y juicio que ponen en cuestión la voz de la víctima. Luego de una examinación minuciosa por parte de los medios de comunicación, redes sociales y agentes de salud y de justicia, la víctima es ubicada en dos posibles lugares: en el polo de 
Víctimas de violencia sexual: construcción de comunidades de creyentes y acceso a la(s) justicia(s).

impotente y desvalida o en el polo opuesto, de quien propicia el encuentro sexual, la que seduce, la que "se lo busca", lo que le sustrae su condición de víctima.

La banalización de la violencia sexual vivida por determinadas mujeres requiere de la construcción de su figura como una "mala víctima": la víctima que es sustraída de su credibilidad, en donde socialmente se presenta como responsable o con un uso oportunista de la situación. Tomemos el ejemplo de un caso muy mediático del 2015 en donde una mujer paraguaya denuncia a los medios haber sido violada sistemáticamente por el Pombero hasta quedar embarazada. La sospecha sobre la víctima es planteada en los diversos comentarios de lectores:

\section{Omar alberto Broemser · (Diario Crónica - Paraguay) \\ Universidad Nacional del Este}

jajajaja q pombero ni q nada, el marido es de la familia de rinoceronte tiene cuernos hasta en la nariz jajaja

Me gusta $\cdot$ Responder $\cdot 8$ de abril de 2015 15:55

Eliana Ayala Musa · (Diario Crónica - Paraguay)

Scuola Italiana Dante Alighieri

24 años con 3 hijos y uno que murió. DIOS MIOOO, en el centro de salud se regalan los preservativos y los anticonceptivos

Me gusta $\cdot$ Responder $\cdot 2 \cdot 8$ de abril de 2015 9:53

Lilian Salinas - (Diario Crónica - Paraguay)

si se dan, pero no quieren usar

Me gusta $\cdot$ Responder $\cdot 1 \cdot 8$ de abril de 2015 18:45 Editado

Ruben Espinoza Lopez · (Diario Crónica - Paraguay)

Administrador en Digital informatica pilar

Le salió a la perfección la historia a la doña, el marido le creyó... jajajajaja... será que a mi mujer también le esta persiguiendo el pombero??

Me gusta $\cdot$ Responder $\cdot 8$ de abril de 2015 19:14 
Guillermo Arevalos Vigo · (Diario Crónica - Paraguay)

San Lorenzo

Hijo de un Bombero es lo.que quiso decir jajjaja

Me gusta $\cdot$ Responder $\cdot 8$ de abril de 2015 9:37

En "Imposible violar a una mujer tan llena de vicios", Despentes $(2013$, p. 45) explica que para poder merecer el atributo de violada se debe haber vivido conforme a las formas legitimadas de victimización. En ese sentido, nos interesa destacar que la dificultad de ser creída no recae solamente en sus creencias en el Pombero sino que son cuestionadas su sexualidad y moralidad (y en este punto son asimilables a los casos de mujeres que denuncian haber sido violadas por personas), acusándola de incurrir a prácticas ilegales (como el aborto o la droga) a fin de convertirla en sospechosa:

Liz Marina Gimenez · (Diario Crónica - Paraguay)

Auxiliar Contable y Administrativo en Alpaca S.A.

yo vi la foto del bebe y es humano, solo parecía que fue abortado y presentaba quemaduras nomas pff mbae aña pompero pio

Me gusta $\cdot$ Responder $\cdot 17 \cdot 8$ de abril de 2015 8:43

Jesse Centurión Chiuzano · (Diario Crónica - Paraguay)

Asunción

Capaz que al vecino se le llame "pombero" como hera joapy... (?) NOOO. Habría que investigar bien a la madre. No es un tema que debe tomarse como broma, si el niño o la niña nació y estuvo agonizando por 7 horas! Podría tratarse de "un zumo de hierbas" para que impidieran que esta pobre criatura NO naciera... Es una gran pena.

Me gusta $\cdot$ Responder $\cdot 8$ de abril de 2015 14:12

Edu Gonzalez G · (Diario Crónica - Paraguay) UCA

Parece que corre la macoña (droga) por san Pedro! Jajaja muy tonto el marido che... Jajaja

Me gusta $\cdot$ Responder $\cdot 8$ de abril de 2015 9:51 
Victimas de violencia sexual: construcción de comunidades de creyentes y acceso a la(s) justicia(s).

Como vemos, los límites de lo creíble en la esfera pública están restringidos a un cierto tipo de vocabulario y una determinada forma dentro de la cual las palabras de la víctima deben amoldarse para ser tomadas como testimonio legal. Aquí vemos como se teje una relación entre género, lengua, creencias que permite comprender los mandatos de la "carrera de la víctima" y los modos en los que se les exige exhibir públicamente su sufrimiento. Eso limita a la víctima, que debe ajustarse a cierto canon que es ajeno a su vivencia, a su idioma, a su cotidianidad (cfr. Das, 2014). Las mujeres pueden haber forjado una relación distinta con el abuso vivido, sin embargo, seguir el "guión de la violación" les exige "hacer de su violación el núcleo narrativo de su subjetividad" y hacer agencia a partir de ese dolor (Theidon, 2011, p. 74).

Lo paradójico es que asumir ese guión es también un espacio de poder que otorga "capital narrativo" (Theidon, 2011, p. 47) en tanto espacio legítimo de enunciación que permite ser creído, pero a su vez, es un espacio de sujeción al lugar de "violada". Organizar la vida conforme a los mandatos de potencial "buena víctima" no deja de ser una forma terriblemente opresiva sobre los cuerpos, subjetividades y libertades de las mujeres.

Siguiendo a Gatti, la figura de la víctima anida múltiples tensiones:

"por su agencia, pues, es pasiva, y sin embargo la literatura y la mirada socioantropológica nos muestran que tiene agencia, y que la tiene, incluso, colectiva; también por su palabra, pues no habla, no puede, pues la palabra - dolorida - se quebró a partir de lo que sea que la llevó a su actual condición, y sin embargo no solo habla - sino que dice muchas más cosas de lo que dicen en su lugar sus muchos voceros - es paradójica también la identidad que otorga a quien puede ostentarla con legitimidad, por mucho que al tiempo la condición de víctima sea poco deseable; y es una figura paradójica también por su extraño equilibrio entre particularidad y universalidad, pues aunque entendemos que el sufrimiento se vive con intensidad intransferible (...) la condición de víctima constituye uno de los catalizadores más intensos de la solidaridad social hoy; esto es, las víctimas son uno - aislados, solos, incomunicados-y son también multitud" (Gatti, 2014, p. 118). 
Hemos reiterado que en el caso de las mujeres víctimas de violencia sexual por parte del Pombero (como en tantos otros), el mecanismo preferencial de resolución no es la denuncia judicial. Es que otra de las paradojas que envuelve a la víctima es que el "guión de la buena víctima" también está introyectado en ella, muchas veces dificultándole la posibilidad de pensarse como tal. Lejos de una mirada ingenua sobre el funcionamiento de la justicia, no pensamos la denuncia judicial de los casos de violencia como la medida del éxito ni como intrínsecamente reparador para la víctima. Aquí vale preguntarse qué mecanismos otorgan legitimidad a las experiencias de justicia y reparación. ¿Alcanza con ser reconocido como víctima? ¿Sólo es víctima quien logra inscribir su caso judicialmente?.

De hecho, Veena Das (2016) sugiere que el silencio de las víctimas de violencia sexual no necesariamente significa "ausencia de competencias lingüísticas" sino que puede ser entendido como una forma de agencia, quizás la única posible para ellas, practicar la "negación activa". Aún si las mujeres eligen no denunciar (porque sabemos que lo hacen), es válido preguntarse: ¿es posible reparar socialmente lo no dicho en términos jurídicos? ¿Cuáles son los alcances y los límites de esta reparación?

\section{LA TRAMA COLECTIVA DE LA VIOLACIÓN: CONSTRUIR UNA COMUNIDAD DE CREYENTES}

\section{"La virginidad no es toda tuya" Poema de Catulo de Roma}

No alcanza con denunciar los hechos, la víctima de violencia sexual debe luchar por conquistar su papel de víctima ante todos, pre-condición para ser audible. Según el Registro Único de Casos de Violencia contra las Mujeres (INDEC 2018, Argentina) de la situaciones de violencia contra las mujeres mayores de 14 años registradas entre 2013 y 2017, apenas el 16,4\% fueron efectivamente judicializadas. Las instituciones judiciales mediante sus códigos procesales piden pruebas (generalmente el tribunal no construye la prueba, se lo solicita a la víctima), si no hay, se desestima el caso. Se hace de la desconfianza política institucional. 
Víctimas de violencia sexual: construcción de comunidades de creyentes y acceso a la(s) justicia(s).

Hablar de pruebas en los casos de violencia sexual es en demasía complejo dado que por lo general las violaciones son experiencias que se hacen al reparo de la vista de otros y, como ya hemos referido, muchas veces las víctimas se animan a romper el silencio después de años. No así en los casos de las víctimas del Pombero, que con mayor frecuencia cuentan sus experiencias casi inmediatamente, sin embargo, el problema radica en que no logran inscribir judicialmente sus casos. En ese sentido, ya sea porque ha pasado mucho tiempo desde el hecho violento o porque el agresor es un ser mitológico, una mujer violada por un jefe, vecino o familiar comparte la misma dificultad de presentar pruebas que una mujer violada por el Pombero. Entonces, ¿qué es una prueba en estos casos? ¿Cuáles son los mecanismos de construcción de la prueba?

Lo que sucede de hecho es que la justicia evalúa la credibilidad de la víctima (a través de un juicio a sus hábitos, su corporalidad, sus gustos, su moral). Eso significa, tomando las palabras de Catoggio, que se "pone de manifiesto el rol configurativo de las creencias en las condiciones de posibilidad de la evidencia" (2019, p. 4). Es decir, la prueba está supeditada a la creencia y, en ese sentido, nos permite "mostrar el carácter contingente de la evidencia, es decir, que los hechos por sí mismos no son portadores automáticos de una "verdad"” (Catoggio, 2019, p. 5), sino que dependen de determinadas creencias colectivas basadas, en este caso, en la confianza que logre despertar la víctima.

Lo que se evalúa es la capacidad de la víctima, que como ya se ha dicho, además de animarse a romper el silencio, también está obligada a convencer a las instituciones estatales de que es una víctima, de que le crean. Llegar a "ser víctima es nada más y nada menos que una vía de acceso a la condición de ciudadano" (Gatti, 2014, p.120). En ese sentido los distintos tipos de denuncias de violencia sexual a las que hacíamos referencia sí expresan importantes diferencias. Así, se da lugar a una serie de mecanismos de credibilidad selectiva atravesados por tensiones de clase, género, etnia y creencias.

Respecto a las creencias, no nos referimos a la adhesión a un conjunto de dogmas explícitos o a una ideología en concreto sino que, siguiendo a De Ípola, concebimos estas creencias como "una 
confianza acordada" propia de la lógica de pertenencia a un colectivo. Se trata de un modo del creer que es indisociable de ser "miembro de" un grupo determinado. (De Ípola, 1997, p.12).

En sintonía con esto, cuando una víctima se anima a romper el silencio generalmente otras mujeres empiezan a contar sus historias, sea o no con el mismo violador. Esas denuncias concatenadas funcionan como respaldo, apoyo y fortalecimiento de la voz de la víctima ante posibles mecanismos de descrédito, eso explica el "efecto contagio" de las acusaciones a un violador. El poder nombrar permite desplegar esa situación (hasta entonces recluida en la intimidad) en el espacio público, hacerla colectiva y tejerse con otras voces y experiencias. Porque ante la dificultad de probar los hechos de violación, la comunidad de creyentes tiene el valor de "testigo".

En el plano más subjetivo, Hercovich explica el efecto que tiene una denuncia (no necesariamente en términos judiciales) sobre otras víctimas, "las víctimas necesitan que les ayuden a confiar en las palabras con las que intentan despejar la oscuridad en la que ocurrió la violación" (2000, p. 7). Porque escuchando a otras se recuerda, se organiza lo ocurrido, se le pone nombre. Por eso, ante las palabras de otra mujer abusada, una víctima puede comprender su propia experiencia de violación, porque no hay un único modo de experimentar y simbolizar la violencia sexual.

El problema es que nuestro ordenamiento jurídico plantea los casos de violencia sexual en términos de la dicotomía "víctima-victimario". Sin embargo, la violación no es un hecho que pueda reducirse a estas categorías. Como lo explica Segato (2010), la violación tiene un efecto disciplinador y pedagogizante más amplio sobre todas las mujeres, reafirmando la centralidad de la posición masculina. Desde este punto de vista, la violación no puede ser sólo entendida como un crimen libidinal ejercido por el violador sobre la víctima, sino como un acto de poder que reafirma una estructura jerárquica donde la posición masculina es la dominante. En ese sentido, no tiene importancia si el violador fue un hombre, un duende o un ser mitológico, sino comprender la violación como restauración de un orden patriarcal. 
Víctimas de violencia sexual: construcción de comunidades de creyentes y acceso a la(s) justicia(s).

Entender la densidad política de la violación permite pasar de la enunciación de una persona (la denuncia con su serie de protocolos) a un acto colectivo, es decir, abandonar el "guión de la buena víctima" que implica la condición de víctima individual, sufriente y pasiva. En los últimos tiempos muchas de éstas estrategias colectivas se han dado por fuera de los mecanismos propuestos por las instituciones de justicia y han girado en torno a construir una "comunidad de creyentes" del relato de la víctima.

Con comunidad de creyentes nos referimos a un colectivo que se organiza en torno a un conjunto de convicciones, que "si bien no se desprenden de la verificación y experimentación, ni, de manera más amplia, de los modos de reconocimiento y control que caracterizan el saber, encuentran sin embargo su razón de ser en el hecho de que dan sentido y coherencia a la experiencia subjetiva de quienes las mantienen" (Hervieu-Léger, 2005, p.122). Lo que sostiene a la comunidad de creyentes, además de los objetos ideales de la convicción (las creencias), son todas las prácticas, los lenguajes, los gestos y los automatismos en los cuales se inscriben sus creencias.

La afinidad entre la consigna "Yo te creo, hermana" y el vocabulario religioso no resulta casual, el mismo concepto de sororidad, tan central en la militancia y producción académica feminista, tiene sus orígenes, según María Luisa Femenías, "cuando se toma conciencia de que la noción de fraternidad tiene como origen "frater" y eso refiere a los varones, al fray. En cuanto se dan cuenta las mujeres apelan a un resabio que mantiene la iglesia que es la noción de sor. Sor como hermana, de la misma manera que fray como hermano. Así se genera el término sororidad como solidaridad femenina" (Avance: Sufragistas, Canal Encuentro, 2017).

Al respecto, Hervieu-Léger señala el problema metodológico que implica sustancializar a la definición de religión, el acto de creer en comunidad, sino que esto debe ser pensado como un modo particular, entre tantos, de organización y funcionamiento del creer. En el caso de las "comunidades electivas" (como podría ser una organización feminista o la comunidad creyente del Pombero), la autora va a señalar que "la especificidad del proceso reside en que la relación con el linaje creyente se construye a partir de la cualidad de 
la relación afectiva que vincula entre sí a los miembros de un grupo de afinidad. No es el reconocimiento de una ascendencia común lo que determina la relación entre las hermanas, es la constatación de la fraternidad vivida (relaciones de elevada intensidad emocional que los propios interesados comparan con vínculos "familiares") la que justifica la invención de una ascendencia común" (cfr. 2005, p. 254).

Así, la consigna "Yo te creo, hermana" adquiere su sentido, acentuando los lazos de hermandad en torno a la violación de otra, logra visibilizar la violación como programa político que excede al sufrimiento de cada víctima. A su vez, la violación siempre requiere un marco, un contexto social que habilite el acto pero también la simbolización, enunciación y escucha de esa experiencia. La violencia sexual requiere una trama colectiva (en donde participa el violador, pero también los "no creyentes": abogados, familiares, médicos, psicólogos, docentes, periodistas, cientistas sociales), por ende, el silencio y la impunidad también son una producción colectiva. Por eso, la denuncia y la reparación no pueden dejar de ser un acto colectivo, como reza la consigna feminista "si tocan a una, nos tocan a todas" porque si la violación es un acto de restauración del poder, hacer comunidad en torno a la víctima también lo es.

\section{CONCLUSIONES}

$\mathrm{Al}$ inicio nos preguntábamos por qué las mujeres salen a gritar que se creen en vez de pedir justicia ante los casos de violaciones. A partir del desarrollo planteado, podemos problematizar aquí las limitaciones de homogeneizar el "guión de la víctima" en un lenguaje exclusivamente jurídico. Justamente nos dedicamos a poner en evidencia cómo la gramática de derechos (entre otras cosas, a través de su categoría de víctima) surge a partir de la exclusión de determinadas experiencias y subjetividades. Y como muchas veces ese mismo guión es internalizado por la víctima dificultando la posibilidad de percibirse como tal.

Buscamos aquí poner atención sobre cómo se tejen los mecanismos de credibilidad, en qué idiomas se expresan, qué violencias logran ser merecedoras de la empatía colectiva y, cuáles, en cambio, 
Víctimas de violencia sexual: construcción de comunidades de creyentes y acceso a la(s) justicia(s).

permanecen banalizadas e invisibles. Es decir, algunas violaciones son más creíbles que otras y la experiencia de la víctima de violencia sexual varía en función de sus propias creencias y qué modos del creer logra movilizar en torno a su violación. Eso sucede porque hay discursos de verdad y modos de simbolizar privilegiados que excluyen a otros al lugar de lo no creíble ni empatizable. Determinados modos de explicar el mundo (como las categorías del discurso jurídico) se convierten en arquetipos normativos que descalifican todo modo otro de interpretación. ¿No existen acaso otras arenas en donde se juegue la pulseada contra la violencia sexual y de género?

Tanto la víctima del caso "la manada", con que iniciamos este artículo, como la mujer que denunció públicamente haber quedado embarazada del Pombero (y tantas otras) comparten la experiencia de dolor y sexo forzado. En torno a ellas se despliegan distintas estrategias de cuidado y reparación ya sean marchas, escraches, consejerías, paros o sean ofrendas, rituales como rociar la casa con agua bendita, no nombrar al Pombero o recluirse cuando cae el sol. Estas estrategias son previas al acceso efectivo a la justicia en su dimensión institucional/gubernamental.

En ambos casos se formaron comunidades creyentes en torno a la experiencia dolorosa de la víctima, que permiten entender la violencia sexual como un acto colectivo y de poder. Sin embargo, una de ellas logró el reconocimiento de las instituciones estatales de justicia. En ese sentido, preguntarnos a qué personas reconocemos en sus vivencias y qué instituciones, grupos, actores reconocen las nuestras es también pensar en las ciudadanías diferenciales y es, a la vez, intentar saldar esa diferencia tejiendo, con más fuerza, estrategias de creencia mutua que propongan otras tramas de experiencias colectivas. Este proceso en ciernes deja abierta la pregunta por el reconocimiento estatal de estas víctimas, reconocidas y hermanadas comunitariamente, pero aún con un acceso desigual a derechos. 


\section{REFERENCIAS}

ARDUINO, I. Melina Romero. La mala víctima en Revista Anfibia, 2014. Disponible en: http://revistaanfibia.com/ensayo/la-mala-victima/

ARDUINO, I. Ni machos, ni fachos en Revista Anfibia,2019. Disponible en: http://revistaanfibia.com/ensayo/ni-machos-ni-fachos/

BAZÁN, A. Devoción popular “Almita Milagrosa”, Salta, 2006.

BERNAL, S. Los mitos de Paraguay y sus contenidos curriculares en el aula de ELE, Instituto Cervantes de Rio de Janeiro, 2008. Disponible en: https://cvc.cervantes.es/ensenanza/biblioteca_ele/ publicaciones_centros/PDF/rio_2008/38_bernal.pdf

BIANCHETTI, C. El proceso de Santificación Popular de Juana Figueroa en Salta, Salta, 2012.

BONNIN, J. New Dimensions of Linguistic Inequality: An Overviewen Language and Linguistics Compass, Volume 7, n 9, p. 500-509, 2013.

BONNIN, J. Discurso politico y cambio de código: la alternancia guaraní/ español en el discurso de Fernando Lugo; Equinox Publishing; Sociolinguistic Studies; 8; 2; -1-2014, p. 271-291.

BOURDIEU, P. ¿Qué significa hablar? Economía de los intercambios lingüísticos. Madrid: Ed. Akal,1985.

BONDAR, C. Angelitos: altares y entierros domésticos. Corrientes (Argentina) y Sur de la Región Oriental de la República del Paraguay en Revista Sans Soleil. n4 España: Universidad del País Vasco, 2012, p. 140 - 167.

BROWNMILLER, S. Contra nuestra voluntad: hombres, mujeres y violación, Barcelona: Planeta, 1981.

BUTLER, J. Marcos de guerra. Las vidas lloradas. Buenos Aires: Paidós, 2010.

CADOGAN, L. Ayvu-Rapyta, textos míticos de los Mbya Guaraní del Guayrá. San Paulo: Ed. UPS, 1959.

CAlVETTI, J. La Juana Figueroa. Buenos Aires: Ediciones Dos Amigos, 1984.

CATOGGIO, S. La construcción de la evidencia en la búsqueda de los desaparecidos: creencias, testimonios y saberes en Papeles del CEIC. International Journal on Colective Identity Research, en prensa, 2019. 
Victimas de violencia sexual: construcción de comunidades de creyentes y acceso a la(s) justicia(s).

CEPEP. Encuesta Nacional de Demografía y Salud Sexual y Reproductiva, Paraguay, 2008.

CERNA VILLAGRA, S. Kuña ha mboriahu: las desventajas de ser mujer y pobre en el ParaguayenRevista Paraguaya desde las Ciencias Sociales, $n^{\circ} 4,2014$, p. 1-25.

CITRO, S. Creando una mujer: ritual de iniciación femenina y matriz simbólica de los géneros entre los toba takshik en Hirsch, Silvia (ed.): Mujeres indigenas en la Argentina, Buenos Aires, Biblos, 2008.

COLOMBRES, A. Seres mitológicos argentinos, Buenos Aires: Emecé Editores, 2001.

COLUCCIO, F. Diccionario de Creencias y Supersticiones, Buenos Aires: Corregidor, 1983.

COLUCCIO, F. Cultos y canonizaciones populares de Argentina. Buenos Aires: Ediciones del Sol, 2010.

DAS, V. Violencia, cuerpo y lenguaje. México: Fondo de Cultura Económica, 2016.

DAS, V. Veena Das: Cuerpos y lenguajes bajo fuego en Revista Ñ, Diario Clarín, 2014. Disponible en: https:/www.clarin.com/rn/ideas/ Cuerpos-lenguajes-fuego_0_ryObKyq5vQ1.html

DAVIS, A. Mujeres, raza y clase. Madrid: Acal, 2004.

DE ÍPOLA, E. Las cosas del creer. Creencia, lazo social y comunidad política. Buenos Aires: Ariel, 1997.

DESPENTES, V. Teoría King Kong. Buenos Aires: Hekht Libros, 2013.

DÍAZ LEDESMA, L. G. El Almamula: Entre el terror, el incesto y la violencia de género. Tesis de Licenciatura. Universidad Nacional de La Plata, 2011.

ESCALADA, S. Mitos y leyendas. Un viaje por la región guaraní, Universidad Nacional de Misiones, Misiones: Editorial Universitaria, 2012.

ESCOBAR, T. El mito del arte y el mito del pueblo, Buenos Aires: Ariel, 2014.

FERNÁNDEZ BRAVO Bravo, Á. comp., Mitos y leyendas de Sudamérica, Buenos Aires: La Marca, 2015.

FLORES PEREZ, E. Narrativas urbanas de acoso sexual. Memorias, afectos y significaciones de las mujeres en la Ciudad de México En: 
Ángulo Recto. Revista de estudios sobre la ciudad como espacio plural, vol. 6, núm. 1, 2014. p. 57-76.

FOGEL et al., Paraguay: La constitución de la identidad femenina en el campoen Centro Paraguayo de Estudio de Población, Asunción, 1992, p. 37-49.

FRIES, L. El caso chileno y la violencia de género en M. Sondereguer y V. Correa (comps.,) Violencia de género en el terrorismo de Estado. Politicas de memoria, justicia y reparación, Quilmes - Lanúsm UNLA, Cedhem, Unqui, 2010.

GATTI, G. El misterioso encanto de las víctimas en Revista de Estudios Sociales, n. 56, 2016, p. 117 -120. Disponible en: https://revistas. uniandes.edu.co/doi/ref/10.7440/res56.2016.09

GÓMEZ, M. El cuerpo por asalto: la amenaza de la violencia sexual en el monte entre las mujeres tobas del oeste de Formosa, en Hirsch, Silvia (ed.): Mujeres indígenas en la Argentina,Buenos Aires: Biblos, 2008.

GUBER,, R. La etnografía: método, campo y reflexividad. Editorial Norma, 2001.

HERCOVICH, I. La violación sexual: un negocio siniestro. Haydeé Birgin (comp.). Las trampas del poder punitivo. El género del derecho penal. Buenos Aires: Biblos, 2000.

HERNÁNDEZ, A. J. C. Memoria familiar y mito: la resignificación del pasado. En Revista de Ciencias Sociales (27), 2011.

HERVIEU-LÉGER, D. La religión, hilo de la memoria. Barcelona: Editorial Herder, 2005.

HOOKS, B. El feminismo es para todo el mundo. Madrid: Traficantes de sueños, 2017.

INDEC, Encuesta Nacional de Victimización, Argentina, 2017.

INDEC, Registro Único de Casos de Violencia contra las Mujeres, Argentina, 2018.

JELIN, E. Los abusos sexuales como crímenes de lesa humanidad y el respeto a la intimidad (Cap. 6). En: La lucha por el pasado. Cómo construimos la memoria social. Buenos Aires: Paidós, 2017. p. 217240.

LAMAS, M. Acoso. ¿Denuncia legítima o victimización? México: Fondo de Cultura Económica, 2018. 
Víctimas de violencia sexual: construcción de comunidades de creyentes y acceso a la(s) justicia(s).

LERNER, G. Black women in white America: a documentary history. New York: Pantheon Books, 1990.

LÓPEZ BREARD, M. Mitos Guaranies, Asunción: Editora Intercontinental, 1994.

LOPEZ PEIRÓ, B. Por qué volvías cada verano. Buenos Aires: Madreselva, 2018.

MANTILLA, J. La experiencia de la Comisión de la Verdad y Reconciliación en el Perú, en M. Sondereguer y V. Correa (comps.,) Violencia de género en el terrorismo de Estado. Políticas de memoria, justicia y reparación, Quilmes - Lanúsm UNLA, Cedhem, Unqui, 2010.

PATEMAN, C. O Contrato sexual, San Pablo: Paz e Terra, 1993

POLLAK, M. Memoria, olvido, silencio. La producción social de identidades frente a situaciones límite. La Plata: Ediciones Al Margen, 2006.

REBOLLEDO MOLLER, E. Testimonios de vida de mujeres rurales de Chiloé en Género y Ruralidad n 2013

RODÓ DE ZÁRATE, M. Hogares, cuerpos y emociones para una concepción feminista del derecho a la ciudad. En Navas Perrone, María Gabriela y Makhlouf de la Garza, Muna, Apropiaciones de la ciudad. Género y producción urbana: la reivindicación del derecho a la ciudad como práctica espacial. Barcelona: Pollen, 2018. p.4471.

SAGOT RODRÍGUEZ, M. ¿Un mundo sin femicidios? Las propuestas del feminismo para erradicar la violencia contra las mujeres". En: Feminismos, pensamiento crítico y propuestas alternativas en América Latina, Buenos Aires: CLACSO, 2017. p. 61-78.

SANDAY, P. R. The socio-cultural context of rape: a cross-cultural study, Journal of Social Issues 37, 1981.

SEGATO, R. La Nación y sus otros. Buenos Aires: Prometeo, 2007.

SEGATO, R. Las estructuras elementales de la violencia. Buenos Aires: Prometeo, 2010.

SEGATO, R. La escritura en el cuerpo de las mujeres asesinadas en Ciudad Juárez. Buenos Aires: Tinta Limón, 2013

SILVESTRI, L. Leonor Silvestri, enemiga pública en Revista Furias, 2017. Disponible en:http://revistafurias.com/leonor-silvestri-enemigapublica/ 
SPIVAK, G. ¿Puede hablar el sujeto subalterno? en Memoria Académica, Orbis Tertius, n. 3, p 1998, . 175-235. Disponible en: http://www. memoria.fahce.unlp.edu.ar/art_revistas/pr.2732/pr.2732.pdf.

SUTTON, B. Terror, testimonio y transmisión: Voces de mujeres sobrevivientes de centros clandestinos de detención en Argentina (1976-1983), Revista Mora, n 21, 2015. p. 5-23.

TARDUCCI, M. Abusos, mentiras y videos. A propósito de la niña wichi en Boletín de Antropología y Educación, n. 05, 2013, p. 7-13. Disponible en: http:/antropologia.institutos.filo.uba.ar/sites/ antropologia.institutos.filo.uba.ar/files/bae_n05a01.pdf

THEIDON, K. Género en transición; sentido común, mujeres y guerra en Cadernos Pagu, n. 37, p. 43-78, 2011.

THEIDON, K. Ocultos a plena luz: los niños nacidos de la violencia sexual en tiempos de guerra en Revista Análisis Político, Bogotá, n. 85, p. 158-172, 2015.

TOLA, F. Constitución del cuerpo femenino entre los tobas (qom) del este formoseño en Hirsch, Silvia (ed.): Mujeres indígenas en la Argentina, Buenos Aires, Biblos, 2008.

TOMASINI, M. E., \& MORALE, M. G. La" mala víctima”: cuerpos, estéticas juveniles femeninas y violencia sexual, 2017.

TORRES, A. La verdadera muerte de Visitación Sivila, Jujuy, 1974.

YERUSHALMI, Y. Reflexiones sobre el olvido, en VVAA, Usos del olvido. Buenos Aires: Nueva Visión, 1989. 